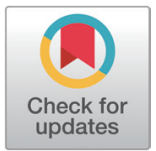

Received: Mar 31, 2021

Revised: Apr 27, 2021

Accepted: May 10, 2021

*Corresponding author

Won-Young Lee

Department of Beef \& Dairy Science, Korea National College of Agricultures and Fisheries, Jeonju 54874, Korea.

Tel: +82-63-238-9214

E-mail: leewy81@korea.kr

Copyright (c) 2021 Korean Society of Animal Sciences and Technology. This is an Open Access article distributed under the terms of the Creative Commons Attribution Non-Commercial License (http:// creativecommons.org/licenses/by$\mathrm{nc} / 4.0 /$ ) which permits unrestricted non-commercial use, distribution, and reproduction in any medium, provided the original work is properly cited.

ORCID

Kwanghyun Cho

https://orcid.org/0000-0003-1564-5656 Yirim Song

https://orcid.org/0000-0002-6940-2097 Joon-Mo Yeo

https://orcid.org/0000-0002-1617-2195 Jin-Ki Park

https://orcid.org/0000-0002-8423-5848

Dong-Wook Kim

https://orcid.org/0000-0003-2647-2690

Seung-Hee Roh

https://orcid.org/0000-0003-0267-8846

Pilnam Seong

https://orcid.org/0000-0003-2915-1059

Won-Young Lee

https://orcid.org/0000-0003-0291-5581

\title{
Analysis of seasonal effect on Korean native cattle (Hanwoo) birth weight
}

\author{
Kwanghyun Cho', Yirim Song ${ }^{1}$, Joon-Mo Yeo' ${ }^{1}$, Jin-Ki Park², \\ Dong-Wook Kim², Seung-Hee Roh ${ }^{3}$, Pilnam Seong ${ }^{4}$ and Won-Young Lee ${ }^{1 *}$ \\ ${ }^{1}$ Department of Beef \& Dairy Science, Korea National College of Agricultures and Fisheries, Jeonju \\ 54874 , Korea \\ ${ }^{2}$ Department of Swine \& Poultry Science, Korea National College of Agriculture and Fisheries, Jeonju \\ 54874 , Korea \\ ${ }^{3}$ National Agricultural Cooperative Federation Hanwoo Genetic Improvement Center, Seosan 31948, Korea \\ ${ }^{4}$ Animal Nutrition \& Physiology Division, National Institute of Animal Science, RDA, Wanju 55365, Korea
}

\begin{abstract}
Recently, summer temperatures have frequently been abnormal in Korea owing to global warming. In summer, a decrease in feed intake rate and biological activity were observed in Hanwoo (Korean Native Cattle), leading to lower production rates in the industry. However, the precise scale of damage was not reported as with other animals of economic value. This study was conducted to investigate the effects of birth season on birth weight in Hanwoo. Data were collected from 100 local breeding farms from 2016 to 2019. A total of 41,081 Hanwoo calves were classified and analyzed by sex, year, month, and season (March-May, spring; June-August, summer; September-November, fall; and December-February, winter) of birth. The birth weight of Hanwoo calves differed according to birth month. The average birth weight of male calves was $30.47 \mathrm{~kg}$ and that of female calves was $28.16 \mathrm{~kg}$. Hanwoo birth weight was the highest in March-born calves and the lowest in July-born calves. The birth weights of calves born in February, March, April, November, and December were significantly larger than those of calves born in July. In addition, the birth weight of Hanwoo calves from the summer was significantly lower than that of calves born in other seasons. Furthermore, Hanwoo steer slaughter age showed a negative correlation, whereas carcass weight had a positive correlation with birth weight. In the beef cattle industry, birth weight is a very important economic characteristic that is related to growth rate. These data will contribute toward planning the reproduction of Hanwoo and analysis of changes in characteristics of economic value owing to high temperatures.
\end{abstract}

Keywords: Hanwoo, Birth weight, Season, Temperature

\section{INTRODUCTION}

Hanwoo are Korean native cattle that have been raised traditionally in the natural environment of Korea. Until the last decade, Hanwoo were used for farming and transportation; however, the purpose of raising Hanwoo was recently changed to good quality meat production with the development of the 
Competing interests No potential conflict of interest relevant to this article was reported.

\section{Funding sources}

This study was supported by the Cooperative Research Program, Rural Development Administration, Korea (grant number PJ01494505).

Acknowledgements

Not applicable.

Availability of data and material Upon reasonable request, the datasets of this study can be available from the corresponding author.

Authors' contributions Conceptualization: Cho K, Lee WY. Data curation: Song Y, Yeo JM, Park JK, Kim DW, Roh SH, Seong P.

Writing - review \& editing: Cho K, Lee WY.

Ethics approval and consent to participate This article does not require IRB/IACUC approval because there are no human and animal participants. economy of Korea. In 2020, according to statistical data from the Korean Statistical Information Service, 3,226,029 Hanwoo were raised in Korea [1]. Since the enactment of the Animal Products Traceability law, carcass character data of each Hanwoo have been recorded in the database of the Korea Institute for Animal Products Quality Evaluation. However, carcass characteristics alone are not sufficient for the analysis of economic characteristics. For the scientific production of Hanwoo, analysis of the changes in economic characteristics should also consider environmental effects including birth weight, feed intake rate, daily weight gain, and reproductive efficiency.

A recent study has highlighted that global climate is changing [2]. In addition to the increase in temperature, there has been an increase in the frequency of extreme events such as the number of hot days and heat waves. In recent years, world warming was a serious challenge to various production systems including livestock production [3]. Especially, in Korea, the increase in summer temperature was considerably more than that in other countries. During summer season weather conditions in Korea are hot (maximum temperature $28.4^{\circ} \mathrm{C}$ ) and humid (maximum humidity 91.4\%) as evidenced by the average climate data [4]. High temperature and humidity reduces the production rate of livestock and increases their mortality.

Birth weight is a very good economic indicator in the beef cattle industry. The birth weight is reported to be positively correlated with daily weight gain [5] and weight at maturity [6]. Other studies have reported that increased birth weight is associated with dystocia, stillbirths, and calf mortality, which are further associated with lower calf performance, and can lead to economic losses $[7,8]$. These differing opinions continue to be debated. Therefore, the aim of the present study was to investigate the effect of birth season on Hanwoo birth weight and other characteristics of economic value. For this purpose, we analyzed the birth weight of Hanwoo calves born during 2016-2019 and verified the correlation between birth weight, birth season, and carcass weight.

\section{MATERIALS AND METHODS}

\section{Data collection}

Data on birth weight was collected from 100 local breeding farms from 2016 to 2019 according to the National Agricultural Cooperative Federation Hanwoo Genetic Improvement Center program. The 41,081 Hanwoo calves (male: 20,978, female: 20,016, Freemartin: 87) enumerated were classified and analyzed by sex, year, month, and seasons. Seasons were classified as spring: March-May, summer: June-August, fall: September-November, and winter: December-February. Slaughter age and carcass weight data were collected from 8,868 Hanwoo castrated steers born between 2016 and 2017. Slaughter age was divided into six groups: < 28 months, 28 months, 29 months, 30 months, 31 months, and $\geq 32$ months. Carcass weight divided three groups: $<435 \mathrm{~kg}$, $435 \mathrm{~kg} \leq$ carcass weight $\leq 486 \mathrm{~kg}$, and $>486 \mathrm{~kg}$.

\section{Statistical analysis}

One-way analysis of variance (ANOVA) was performed for the compare average birth weight data using Statistical Analysis System (SAS) 9.4 software (SAS, Cary, USA); the Duncan's multiple comparison test was used for making comparisons among groups. All data are expressed as mean \pm SD. The null hypothesis was rejected when the probability was $p<0.05$.

The general linear model procedure of the SAS software was used to test the significance of birth weight traits. The linear model for birth weight was as follows:

$$
\mathrm{y}_{\mathrm{ijke}}=\mu+\mathrm{M}_{\mathrm{i}}+\mathrm{SA}_{\mathrm{j}}+\mathrm{Car}_{\mathrm{k}}+\mathrm{e}_{\mathrm{ijke}}
$$


where,

$y_{\mathrm{ijke}}$ represents Hanwoo birth weight

$\mu$ is the total mean

$\mathrm{M}_{\mathrm{i}}$ is the ith fixed effect of calving month (1 to 12)

$\mathrm{SA}_{\mathrm{j}}$ is the jth fixed effect of slaughter age group (1 to 6)

$\mathrm{Car}_{\mathrm{k}}$ is the kth fixed effect of carcass weight group (1 to 3)

$\mathrm{e}_{\mathrm{ijke}}$ is the residual error.

The least squares method was used to estimate the environmental effects on calving month, season, and carcass traits. The linear model was analyzed using the SAS 9.4 package and variance analysis was performed using a Type III squared fit for unbalanced data among the four squares presented in the SAS/general linear model analysis. The statistical significance of the differences between the least squares averages of the treatments was tested with the following null hypothesis at a significance level of $1 \%$ : Ho: least squares means $(\operatorname{LSM})(i)=\operatorname{LSM}(j)$, where LSM $(i(j))$ is the least squares average of the $I(j)$ effects $(I \neq j)$.

\section{RESULTS AND DISCUSSION}

\section{Effect of birth month on birth weight}

To determine the correlation between birth month and birth weight in Hanwoo calves, a total of 20,978 male and 20,016 female calves were analyzed. The average birth weight of male calves was $30.47 \mathrm{~kg}$ and that of female calves was $28.16 \mathrm{~kg}$ (Table 1). The birth weight of male calves was significantly more than that of female calves. Many factors influence the growth of a developing fetus, including sex. Previous reports have shown that female calves, twins, and calves born to firstparity cows had lower birth weight than male calves, single births, or calves born to multiparous cows, respectively [9]. Another report described that male calves were heavier than their contemporary females throughout the pre-weaning growth period [10]. Commonly, bull carcasses showed higher yield but lower quality than those of cows and steers. According to data from 1970 to 2006 , Hanwoo birth weight was $24.35 \mathrm{~kg}$ which is lower than in the present study [11]. Another research group also described a lower birth weight of Hanwoo calves, $23.02 \mathrm{~kg}$ (1974-1995) [12]. National Hanwoo genetic evaluations are implemented by recording birth weight, weaning weight,

Table 1. The monthly average of Hanwoo calf's birth weight in 2016-2019 period

\begin{tabular}{|c|c|c|c|c|}
\hline \multirow{2}{*}{ Month } & \multicolumn{2}{|c|}{ Male } & \multicolumn{2}{|c|}{ Female } \\
\hline & Numbers of calf & Mean of birth weight (kg \pm SD) & Numbers of calf & Mean of birth weight $(\mathrm{kg} \pm \mathrm{SD})$ \\
\hline 1 & 85 & $29.48 \pm 4.19^{d}$ & 80 & $27.80 \pm 4.57^{\mathrm{bc}}$ \\
\hline 3 & 4,572 & $30.84 \pm 4.46^{a}$ & 4,515 & $28.50 \pm 3.84^{\mathrm{a}}$ \\
\hline 4 & 2,488 & $30.63 \pm 4.36^{\mathrm{ab}}$ & 2,120 & $28.19 \pm 3.78^{\mathrm{abc}}$ \\
\hline 7 & 180 & $29.11 \pm 4.48^{d}$ & 178 & $27.59 \pm 4.08^{\mathrm{c}}$ \\
\hline 8 & 4,662 & $30.09 \pm 4.03^{\mathrm{bc}}$ & 4,576 & $27.71 \pm 3.69^{b c}$ \\
\hline 9 & 2,821 & $30.56 \pm 4.42^{\mathrm{ab}}$ & 2,466 & $28.34 \pm 3.82^{\mathrm{ab}}$ \\
\hline 10 & 1,272 & $30.23 \pm 4.17^{\mathrm{ab}}$ & 1,124 & $28.13 \pm 3.70^{\mathrm{abc}}$ \\
\hline
\end{tabular}


yearling weight, carcass weight, eye muscle area, backfat thickness, and marbling score. The yearling weight was $315.54 \mathrm{~kg}$ in 1998, and had increased to $355.06 \mathrm{~kg}$ in 2011. Yearling weight and carcass weight have improved remarkably over the past 15 years [13]. In recent years, breeding of Hanwoo has been aimed at increasing carcass weight that related with increasing economic benefit of farm.

The male calves born in March were the largest, weighing $30.84 \mathrm{~kg}$. The July-born male calves weighing $29.11 \mathrm{~kg}$ were the smallest. Male calves born in February, March, April, September, October, November, and December were significantly larger than the calves born in January, June, and July. The female calves born in March were the largest in comparison to those born in the other months and weighed $28.5 \mathrm{~kg}$. The July-born female calves weighed $27.59 \mathrm{~kg}$ and were smaller than those born in the other months. Female calves born in March, September, and November were significantly larger than the July-born calves. In Korea, the climate in July is very hot and humid. During this period, the feed intake rate and growth gain is reduced in domestic animals. Typically, fetus growth is substantial during the last period of the pregnancy. Pregnant cows cannot consume enough feed in July and this influences the growth of the fetus.

\section{Effect of birth season on birth weight}

To analyze the correlation between birth season and birth weight in Hanwoo calves, the seasons were divided as spring (March-May), summer (June-August), autumn (September-November), and winter (December-February). The birth weights of male calves were $30.69 \pm 4.41,30.03 \pm 4.05$, $30.46 \pm 4.35$, and $30.62 \pm 4.35 \mathrm{~kg}$ in spring, summer, autumn, and winter, respectively (Table 2). Male Hanwoo calves born in spring were the largest and the smallest were summer-born. Spring born calves were significantly larger than summer- and autumn-born calves. In addition, male Hanwoo calves from summer were significantly smaller than those born in the other seasons. The birth weights of female calves were $28.35 \pm 3.81,27.72 \pm 3.69,28.28 \pm 3.80$, and $28.24 \pm 3.90 \mathrm{~kg}$ in spring, summer, autumn, and winter, respectively. Female Hanwoo calves born in spring were the largest and the smallest were summer born. Female Hanwoo calves born in the summer were significantly smaller than those born in the other seasons. The birth weight of spring-, autumn-, and winter-born calves were not significantly different from each other. A previous study from Brazil showed that the mean birth weight of the calves did not differ among the seasons of the year at birth and calf sexes; however, cows with below average lengths of gestation calved lighter calves [14]. A study conducted in Texas reported that year, calf sex, dam age, stocking rate, birth season, birth weight, and weaning age were significant factors affecting weaning weight. Fall-born calves were heavier at weaning $(267.6 \mathrm{~kg})$ than either winter- $(252.0 \mathrm{~kg})$ or spring-born calves $(240.9 \mathrm{~kg})$ [15]. However, the climate of Korea is very different from that of these countries. The temperature on the Korean peninsula is increasing continuously, and hot and humid summers and cold and dry winter are expected. According to these climatic conditions in Korea, the effects of birth seasons on Hanwoo birth weight will be different from those observed in cattle in other countries.

Table 2. The seasonal average of Hanwoo calf's birth weight in 2016-2019 period

\begin{tabular}{|c|c|c|c|c|}
\hline \multirow{2}{*}{ Season } & \multicolumn{2}{|r|}{ Male } & \multicolumn{2}{|r|}{ Female } \\
\hline & Numbers of calf & Mean of birth weight $(\mathrm{kg} \pm \mathrm{SD})$ & Numbers of calf & Mean of birth weight $(\mathrm{kg} \pm \mathrm{SD})$ \\
\hline Spring & 7,700 & $30.69 \pm 4.41^{\mathrm{a}}$ & 7,183 & $28.35 \pm 3.81^{\mathrm{a}}$ \\
\hline Summer & 5,126 & $30.03 \pm 4.05^{\mathrm{c}}$ & 4,997 & $27.72 \pm 3.69^{b}$ \\
\hline Autumn & 4,362 & $30.46 \pm 4.35^{b}$ & 3,841 & $28.28 \pm 3.80^{\mathrm{a}}$ \\
\hline Winter & 3,790 & $30.62 \pm 4.35^{\mathrm{ab}}$ & 3,995 & $28.24 \pm 3.90^{\mathrm{a}}$ \\
\hline
\end{tabular}




\section{Correlation of birth weight with carcass characteristics in Hanwoo steers}

To determine the correlation of birth weight with carcass month and weight, 8,868 Hanwoo steers born in 2016-2017 were analyzed. The results of the linear model for BW showed that the Juneborn male Hanwoo calves were the smallest (Table 3). In addition, the slaughter age had a negative correlation with birth weight (Table 3). This data indicates that slaughter age was increased to ensure adequate carcass weight which in turn was related to the period in which cattle were raised. Furthermore, carcass weight had a positive correlation with birth weight (Table 3). The group with small carcass weight ( $<435 \mathrm{~kg}$ ) had a birth weight of $28.94 \pm 0.11 \mathrm{~kg}$, and the medium (435-486 $\mathrm{kg}$ ) and large (> $486 \mathrm{~kg}$ ) carcass weight groups had a birth weight of $30.41 \pm 0.11 \mathrm{~kg}$ and $32.29 \pm$ $0.12 \mathrm{~kg}$, respectively.

Climatic conditions affect animal performance. Thermal stress lead to energy maintenance requirements increase and growth rates reduce can result in sizable economic losses to producers of beef cattle. However, very little information is available on seasonal effects in Hanwoo production traits including quality and yield grade in Korea. A previous report described that both marbling score and quality grade of Hanwoo steer carcasses were generally the best in autumn and the worst in spring. In addition, yield grade of Hanwoo steer carcasses was the lowest in winter (November to January) and the highest in spring and summer (May to September) [4].

The temperature-humidity index (THI) can be used to determine the influence of heat stress on the productivity of farm animals. THI is divided into categories that potentially indicate the level of heat stress. A previous study identified a THI $<71$ as the thermal comfort zone, 72 to 79 as mild heat stress, 80 to 90 as moderate heat stress, and $>90$ as severe heat stress [16]. Weather conditions in the Korean peninsula are hot and humid during summer, and THI values are between 73 and 80

Table 3. The correlation between birth weight and carcass character of Hanwoo steer in 2016-2017 period

\begin{tabular}{lrc}
\hline Group & LSMean of birth weight (kg \pm SE) \\
\hline Calving month & 1 & $30.4386 \pm 0.63635$ \\
2 & $30.8405 \pm 0.10844$ \\
3 & $31.0923 \pm 0.09425$ \\
4 & $30.8508 \pm 0.12395$ \\
5 & $30.3337 \pm 0.21621$ \\
6 & $29.6589 \pm 0.32284$ \\
7 & $30.0370 \pm 0.45547$ \\
8 & $30.2804 \pm 0.09523$ \\
9 & $30.9490 \pm 0.11635$ \\
10 & $30.5441 \pm 0.17592$ \\
11 & $30.2572 \pm 0.36281$ \\
12 & $31.2719 \pm 0.38769$ \\
Slaughter age (month) & 28 & $31.1488 \pm 0.18447$ \\
28 & $31.1395 \pm 0.15929$ \\
29 & $30.6864 \pm 0.13033$ \\
30 & $30.3510 \pm 0.11915$ \\
31 & $30.1654 \pm 0.11995$ \\
$>32$ & $29.7860 \pm 0.11762$ \\
$<435$ & $28.9396 \pm 0.10737$ \\
$435-486$ & $30.4118 \pm 0.10561$ \\
$>486$ & $32.2872 \pm 0.11517$ \\
\hline
\end{tabular}


in summer [4]. According to Armstrong's classification, the summer season resulted in moderate stress to Hanwoo. Therefore, the heat stress during late gestation is related to lower birth weight of calves, which suggests compromised fetal growth [17]. Furthermore, the heat stress has negative affect on Hanwoo industry including reduction of reproductive pergormance and fetal development [18]. However, in this study we focused correlation of birth weight and other economic characters during seasonal changing.

In conclusion, our study investigated the birth weight pattern in Hanwoo during different months and seasons and evaluated the seasonal effect of heat stress on characteristics of economic value. Specifically, the birth weight of Hanwoo calves in the summer season was significantly reduced thereby influencing growth rate after weaning. In addition, birth weight had a negative correlation with slaughter age and a positive correlation with carcass weight. This report contributes toward evaluating the effect of high temperature on performance characteristics and improving breeding strategies and production management systems of Hanwoo for overall superior performance.

\section{REFERENCES}

1. Koran Statistical Information Service [KOSIS]. Livestock trend survey. 2020 [cited $2021 \mathrm{Feb}$ 20].https://kosis.kr/statHtml/statHtml.do?orgId=101\&tblId=DT_1EO221\&conn_path=I2

2. Pasqui M, Di Giuseppe E. Climate change, future warming, and adaptation in Europe. Anim Front. 2019;9:6-11. https://doi.org/10.1093/af/vfy036

3. Bernabucci U. Climate change: impact on livestock and how can we adapt. Anim Front. 2019;9:3-5. https://doi.org/10.1093/af/vfy039

4. Piao MY, Baik M. Seasonal variation in carcass characteristics of Korean cattle steers. Asian-Australas J Anim Sci. 2015;28:442-50. https://doi.org/10.5713/ajas.14.0650

5. Bailey CB, Mears GJ. Birth weight in calves and its relation to growth rates from birth to weaning and weaning to slaughter. Can J Anim Sci. 1990;70:167-73. https://doi.org/10.4141/ cjas90-019

6. Meyer K. Estimates of genetic parameters for mature weight of Australian beef cows and its relationship to early growth and skeletal measures. Livest Prod Sci. 1995;44:125-37. https:// doi.org/10.1016/0301-6226(95)00067-4

7. Linden TC, Bicalho RC, Nydam DV. Calf birth weight and its association with calf and cow survivability, disease incidence, reproductive performance, and milk production. J Dairy Sci. 2009;92:2580-8. https://doi.org/10.3168/jds.2008-1603

8. Johanson JM, Berger PJ. Birth weight as a predictor of calving ease and perinatal mortality in Holstein cattle. J Dairy Sci. 2003;86:3745-55. https://doi.org/10.3168/jds.S00220302(03)73981-2

9. Dhakal K, Maltecca C, Cassady JP, Baloche G, Williams CM, Washburn SP. Calf birth weight, gestation length, calving ease, and neonatal calf mortality in Holstein, Jersey, and crossbred cows in a pasture system. J Dairy Sci. 2013;96:690-8. https://doi.org/10.3168/ jds.2012-5817

10. Raphaka K, Dzama K. Sex of calf and age of dam adjustment factors for birth and weaning weight in Tswana and composite beef cattle breeds in Botswana. S Afr J Anim Sci. 2009;39:296-300. https://doi.org/10.4314/sajas.v39i4.51133

11. Hwang JM, Choi JG, Kim HC, Choy YH, Kim S, Lee C, et al. Genetic relationship of gestation length with birth and weaning weight in Hanwoo (Bos taurus coreanae). Asian-Australas J Anim Sci. 2008;21:633-9. 
12. Choi SB, Lee JW, Kim NS, Na SH, Keown JF, Van Vleck LD. Estimation of genetic parameters for direct, maternal and grandmaternal genetic effects for birth, weaning and six month weights of Hanwoo (Korean cattle). Asian-Australas J Anim Sci. 2000;13:149-54. https://doi. org/10.5713/ajas.2000.149

13. Park B, Choi T, Kim S, Oh SH. National genetic evaluation (system) of Hanwoo (Korean native cattle). Asian-Australas J Anim Sci. 2013;26:151-6. https://doi.org/10.5713/ ajas.2012.12439

14. Vieira Rezende E, José Reis I, Cristian Campos C, Maria Santos R. Influence of gestation length, seasonality, and calf sex on birth weight and placental retention in crossbred dairy cows. Ciênc Anim Bras. 2020;21:e-52881. https://doi.org/10.1590/1809-6891v21e-52881

15. Gaertner SJ, Rouquette FM Jr, Long CR, Turner JW. Influence of calving season and stocking rate on birth weight and weaning weight of Simmental-sired calves from Brahman-Hereford F1 dams.J Anim Sci. 1992;70:2296-303. https://doi.org/10.2527/1992.7082296x

16. Armstrong DV. Heat stress interaction with shade and cooling. J Dairy Sci. 1994;77:2044-50. https://doi.org/10.3168/jds.S0022-0302(94)77149-6

17. Collier RJ, Doelger SG, Head HH, Thatcher WW, Wilcox CJ. Effects of heat stress during pregnancy on maternal hormone concentrations, calf birth weight and postpartum milk yield of Holstein cows.J Anim Sci. 1982;54:309-19. https://doi.org/10.2527/jas1982.542309x

18. Sa SJ, Jeong J, Cho J, Lee SH, Choi I. Heat waves impair cytoplasmic maturation of oocytes and preimplantation development in Korean native cattle (Hanwoo). Korean J Agric Sci. 2018;45:493-8. https://doi.org/10.7744/kjoas.20180072 